\title{
CFD Research on Optimal Designing of Radiator Axial Fan
}

\author{
Siddhan Sivakumar
}

\begin{abstract}
The scope of the project is to improve the design of the given axial fan with shroud by doing CFD analysis also to derive the performance curve of the fan and to extract the fan efficiency curve. The CFD model was developed to predict the air flow through the fan with shroud system. Simulations were performed by $\mathrm{CFX}$ solver for the following objectives. The model and CFD analysis was built using the following parameters like, Speed of the fan 3100 RPM, Diameter of the fan $365 \mathrm{~mm}$, input power of the motor $325 \mathrm{~W}$ and Torque $0.75 \mathrm{~N}-\mathrm{m}$. from the analysis it is observed that the high pressure regions are occurred at the areas where split of volute started and the tongue areas. Performance curve of radiator fan is calculated and plotted for different pressure drop like 50 Pa,140 Pa,210 Pa,270 Pa,310 Pa and therespective Volume flow rate also predicted.
\end{abstract}

Keywords - CFD, Radiator Fan, Pressure Head

\section{INTRODUCTION}

A substantial proportion of the noise in automotive off highway machines originates from the radiator cooling fan. the demands on cooling fan are increasing due to the need to reject more heat from compact machines with higher engine power density. Also, as a result of tighter exhaust emissions legislations a charge of air cooler or additional charge air cooling is often required. The operating point of the fan in a system is determined by the system resistance (that is the pressure at a given flow rate which the fan needs to overcome) and the performance curves of the fan.

The operating point of the fan in a system is determined by the system resistance (that is the pressure at a given flow rate which the fan needs to overcome) and the performance curves of the fan.Usually the system pressure drop varies according to the following formula:

$$
\mathrm{P}=\mathrm{KQ}^{\mathrm{n}}
$$

Where, P - Pressure drop across the complete system

$\mathrm{K}$ - Constants of the System

Q - Volume flow rate of the Air through the Radiator

The extended use of axial flow fans for fluid movement and heat transfer has resulted in detailed research into the performance attributes of many designs [1-2]. Computational fluid dynamics have been performed to validate the performance of axial fans and their flow behaviours [3-4].However, the more-practical example of cooling a heated engine using an axial flow fan has received more attention in regards to understanding flow behaviours and heat transfer [5-7].In this paper The CFD model was developed to predict the air flow through the fan with shroud system. Simulations were performed by CFX[8] solver for the following objectives.

Revised Manuscript Received on August 14, 2019.

Siddhan Sivakumar, Assistant Professor-III, Department of Mechanical Engineering, Kumaraguru college of Technology, coimbatore, India. (E-mail:sivakumar.siddhan.mec@kct.ac.in)
- To improve the flow rate of the fan

- To predict the pressure distribution of fan

- To determine the recirculation areas in the fan

- To derive the performance curve of the fan

- To extract the fan efficiency curve

\section{MODEL INFORMATION}

\section{a. Geometry Details}

The modelling of given geometry was performed in SOLIDWORKS CAD package from the required information related to the geometry of the Fan and Shroud assembly. The basic input details that go into the model building are the Fan and Shroud

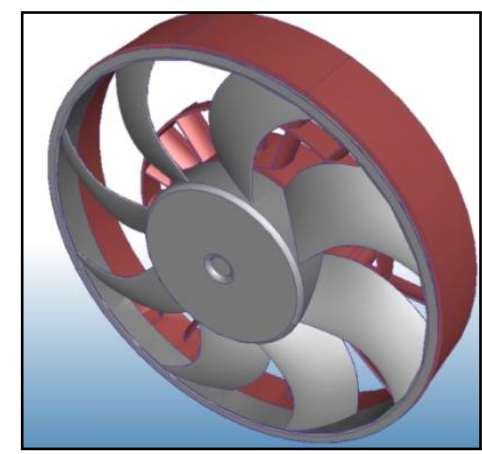

Fig. 1: 3D- Model of the Fan and Shroud Assembly

Figure 1and Figure 2 shows the sample assembly of the Fan and Shroud Assembly. The specifications of the assembly are shown in Table 1.All the required information related to the geometry of the Fan and Shroud was referred from the referenced drawing. The model and CFD analysis was built using the data provided in Table 1

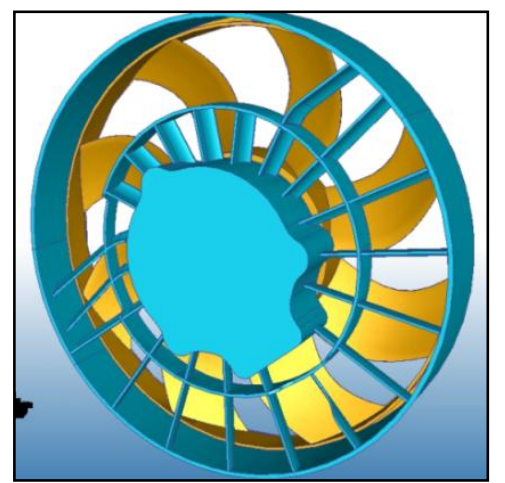

Fig.. 2. Model of Fan and Shroud Assembly

Published By: 
b. Computational fluid dynamics model

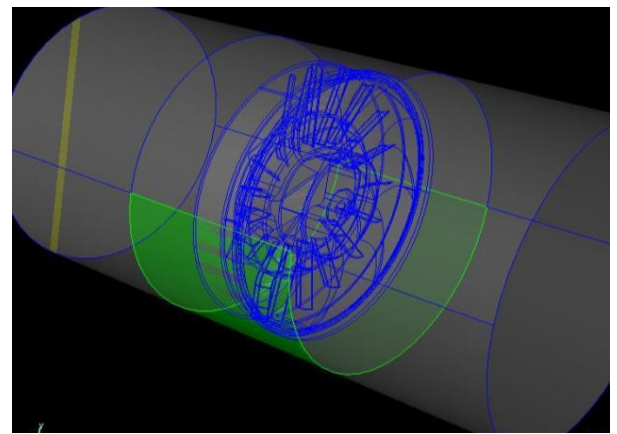

Fig. 3. CFD Flow domain model of the Fan and Shroud Assembly

Table 1: Input details for Fan CFD analysis

\begin{tabular}{|c|c|}
\hline \multicolumn{2}{|c|}{ Fan Details } \\
\hline Speed of the Fan(RPM) & 3100 \\
\hline Diameter of the Fan $(\mathrm{mm})$ & 365.00 \\
\hline \multicolumn{2}{|c|}{ Motor Specification } \\
\hline Input Power( W) & 324.1 \\
\hline Output Power( W) & 246.8 \\
\hline Torque ( N-m) & 0.75 \\
\hline Efficiency & 0.762 \\
\hline
\end{tabular}

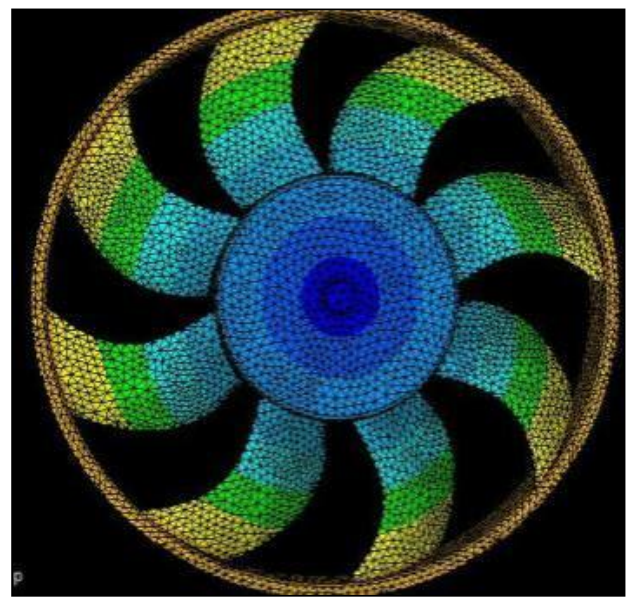

Fig. 4. Meshed model of Fan and Shroud Assembly (Frontside)

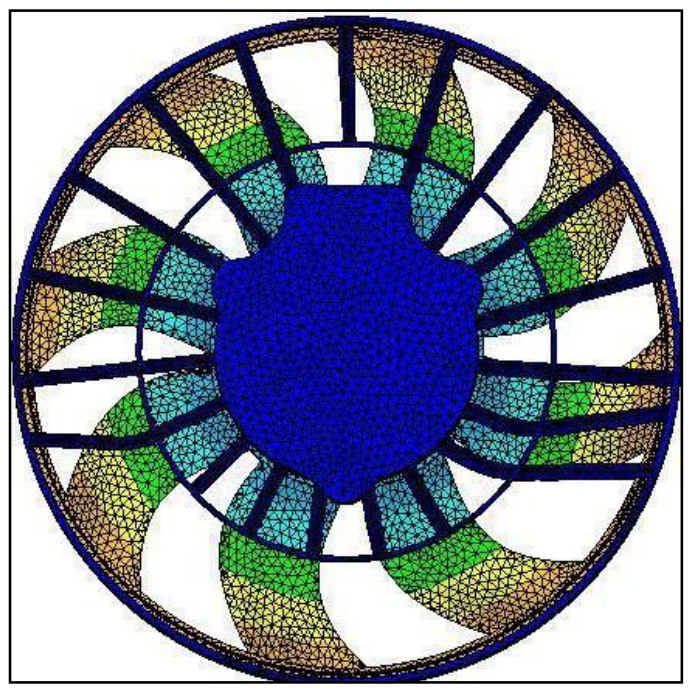

Fig. 5. Meshed model of Fan and Shroud Assembly(back side)
Figure 3 shows the flow domain model of fan and shroud assembly for the CFD analysis. And mesh automatically done by ANSYS Workbench Tool. Details of the Mesh parameters are shown in the table 2.

Table 2: Meshing Details

\begin{tabular}{|c|c|c|}
\hline Domain Name & Domain Type & $\begin{array}{c}\text { No. Of } \\
\text { Elements }\end{array}$ \\
\hline Fan Region & solid & 500000 \\
\hline $\begin{array}{c}\text { Shroud and } \\
\text { External Region }\end{array}$ & Solid and Fluid & 500000 \\
\hline
\end{tabular}

\section{c. CFD Methodology}

The air flow was assumed to be unsteady state, three dimensional, turbulent and incompressible. After the creation of the grid, the managing program reads all the necessary information regarding the boundary conditions, material Properties and initial parameters and writes them in the CFX. Once a grid has been read into software, all remaining operations are performed within the solver manager. The solution algorithm is the segregated solver. In this approach, the governing equations are solved sequentially with the above analysis setup.

Mesh has been created with care such that the regions with high velocity and pressure variation have fine meshes to capture the field variables accurately. All the outlet, inlet and wall boundary conditions are represented in the table 3 . as required. The model and CFD analysis was built using the following parameters like, Speed of the fan 3100 RPM, Diameter of the fan $365 \mathrm{~mm}$, input power of the motor 325 $\mathrm{W}$ and Torque $0.75 \mathrm{~N}-\mathrm{m}$

- SIMPLE algorithm

- K-Epsilon turbulence model

- Standard wall functions treatment

- Second order upwind difference schemes for discretization equations

- Unsteady state calculation of fan and shroud with prescribed mass flow rate

- Standard air properties

- Rotating frame of reference given as RPM - 3100

\section{d. Boundary conditions}

Table .3: Boundary conditions considered for Assembly

\begin{tabular}{|l|l|l|}
\hline Inlet & Outlet & Output \\
\hline $\begin{array}{l}\text { Pressure } \\
-0 \mathrm{~Pa}\end{array}$ & Pressure - 0 Pa & $\begin{array}{l}\text { Maximum Flow } \\
\text { rate }\end{array}$ \\
\hline $\begin{array}{l}\text { Pressure } \\
-0 \mathrm{~Pa}\end{array}$ & $\begin{array}{l}80 \% \text { Maximum } \\
\text { Flow rate }\end{array}$ & Pressure drop \\
\hline $\begin{array}{l}\text { Pressure } \\
-0 \mathrm{~Pa}\end{array}$ & $\begin{array}{l}60 \% \text { Maximum } \\
\text { Flow rate }\end{array}$ & Pressure drop \\
\hline $\begin{array}{l}\text { Pressure } \\
-0 \mathrm{~Pa}\end{array}$ & $\begin{array}{l}50 \% \text { Maximum } \\
\text { Flow rate }\end{array}$ & Pressure drop \\
\hline $\begin{array}{l}\text { Pressure } \\
-0 \mathrm{~Pa}\end{array}$ & $\begin{array}{l}30 \% \text { Maximum } \\
\text { Flow rate }\end{array}$ & Pressure drop \\
\hline
\end{tabular}

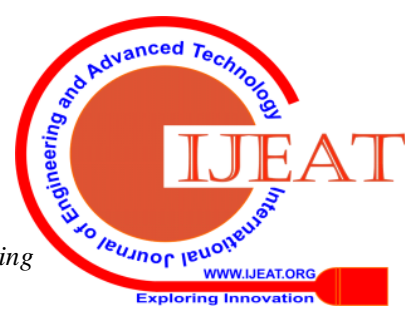




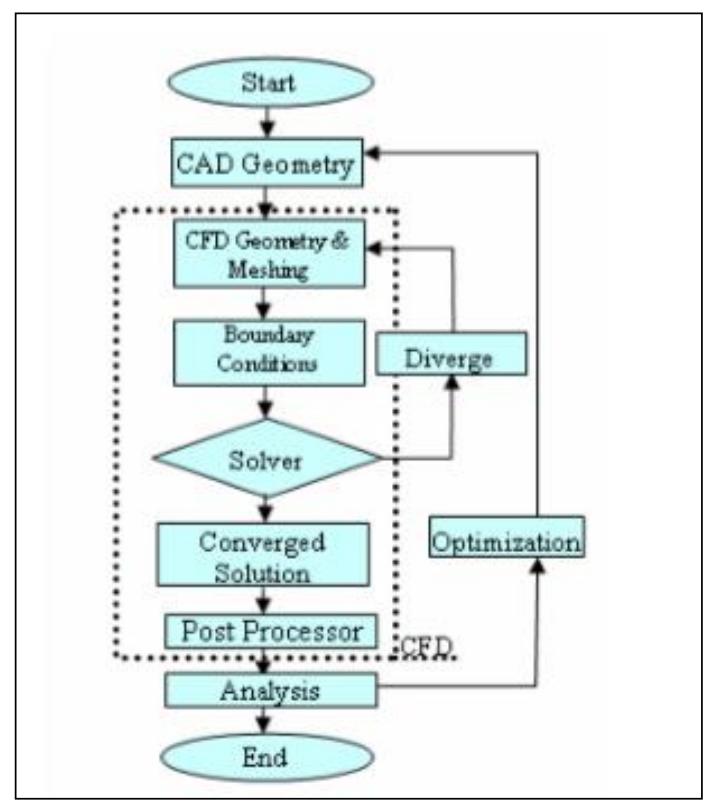

Fig. 6. Flowchart for CFD Methodology

\section{RESULTS AND DISCUSSION}

From the analysis of Fan and shroud assembly it is observed that the high pressure regions are occurred at the areas where split of volute started and the tongue areas. It was realized that the lot of recirculation areas were found in the flow path. This recirculation will lead to the cavitation's and erosion. So, the care should be taken for streamlining the flow in the flow path to avoid recirculation and separation of flow. Performance curve of radiator fan is calculated and plotted for different pressure drop like 50 $\mathrm{Pa}, 140 \mathrm{~Pa}, 210 \mathrm{~Pa}, 270 \mathrm{~Pa}, 310 \mathrm{~Pa}$ and the respective volume flow rate also predicted.

\section{a. Summary of Result for Pressure Distribution}

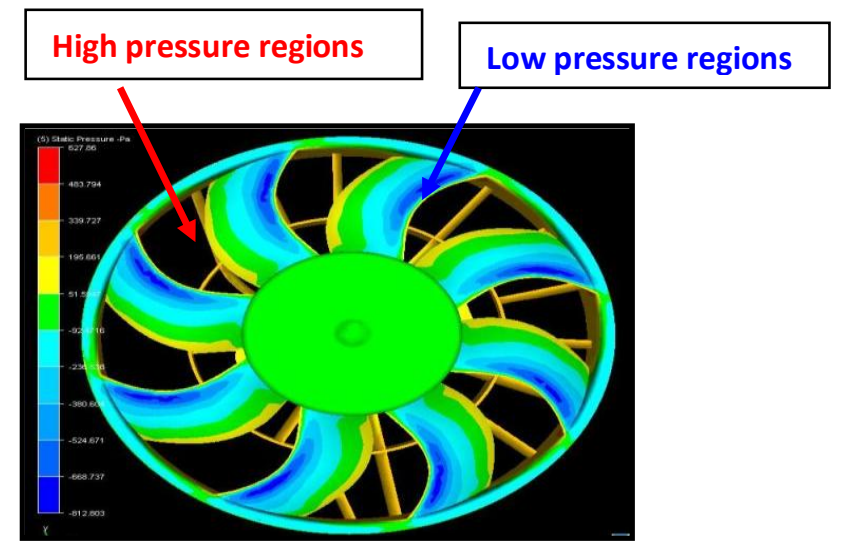

Fig. 7. Pressure distribution plot for fan

Figure 7 shows the pressure distribution of the whole fan. The high pressure regions are occurred at the areas where split of volute started and the tongue areas.

\section{b. Summary of Result for Velocity Distribution}

Figure 8 shows the flow vectors on a plane taken along the entire periphery of the impeller of the fan. From the figure its observed that the low pressure occurs along the centre portion of the fan.

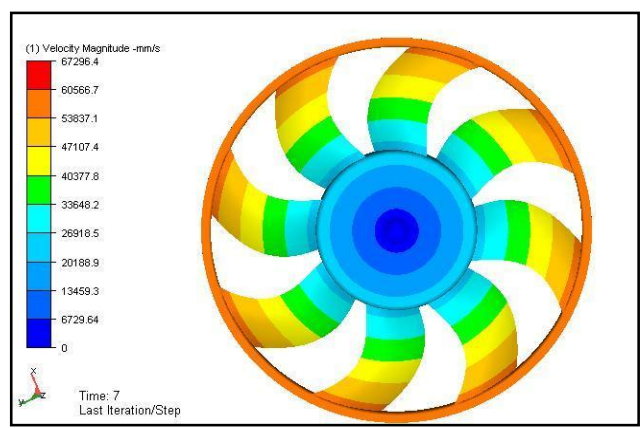

Fig. 8. Velocity distribution plot for fan

Figure 9 shows the velocity vectors plot of the fan on a plane taken along the entire periphery of the impeller of the fan. From the figure its observed that the stream line along the entire assembly of fan and shroud is uniform. it means the resistance due flow with the assembly is minimized for given boundary conditions. it will leeds to improve the efficiency of the fan assembly.

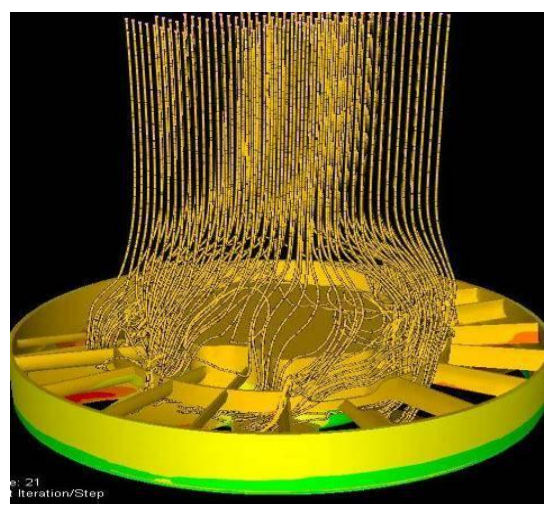

Fig. 9. Velocity vector distribution plot for fan

c. Summary of Performance analysis of Fan and shroud assembly

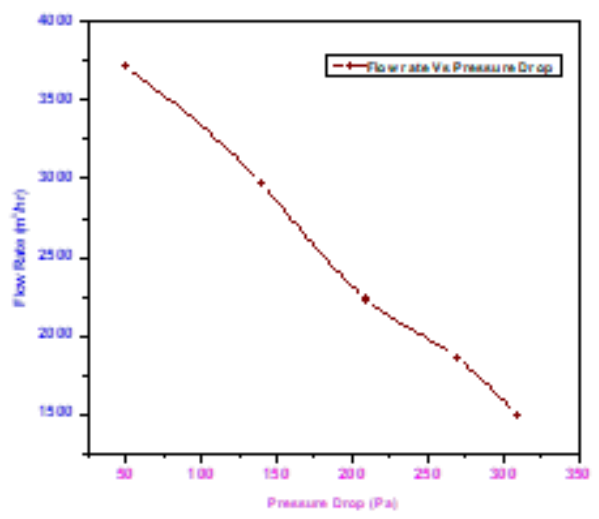

Fig. 10. Performance curve for fan

Performance curve of radiator fan is calculated and plotted for different pressure drop like $50 \mathrm{~Pa}, 140 \mathrm{~Pa}, 210 \mathrm{~Pa}$ ,270 $\mathrm{Pa}, 310 \mathrm{~Pa}$ and the respective Volume flow rate also predicted. From the figure 10 it s observed that the volume flow rate is decreased with respect to pressure drop.

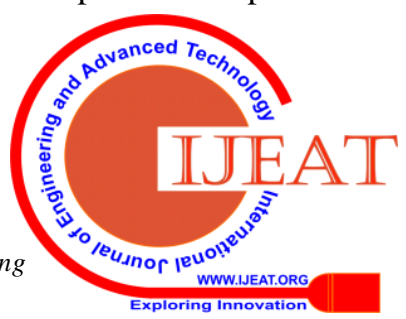


The efficiency of a fan is a measure of its mechanical performance. It is defined as the ratio of the useful power delivered by the fan (Fluid power) to the power supplied to the fan shaft (brake power). The efficiency of the fan is expressed in percent and can be calculated from the torques values given by CFX.To calculate water horsepower the flow rate in gpm and the total dynamic head (TDH) in feet must be known. Water horsepower can be calculated using equations. The efficiency of a fan is determined by actual test. All parameters required for the determination of water horsepower are recorded while brake horsepower is measured. The efficiency range to be expected varies with the fan size, type and design. However, it is normally between 65 and 80 percent. A fan should be selected for a given application so that it will operate close to its point of maximum efficiency.

\section{CONCLUSION}

The model and CFD analysis was built using the following parameters like, Speed of the fan 3100 RPM, Diameter of the fan $365 \mathrm{~mm}$, input power of the motor 325 $\mathrm{W}$ and Torque $0.75 \mathrm{~N}-\mathrm{m}$. From the analysis it is observed that the high pressure regions are occurred at the areas where split of volute started and the tongue areas.Performance curve of radiator fan is calculated and plotted for different pressure drop like $50 \mathrm{~Pa}, 140 \mathrm{~Pa}, 210 \mathrm{~Pa}$ ,270 $\mathrm{Pa}, 310 \mathrm{~Pa}$ and the respective Volume flow rate also predicted. The efficiency range to be expected varies with the fan size, type and design. However, it is normally between 65 and 80 percent

\section{REFERENCES}

1. Gimenez J., Ramajo D., Nigro N., Particle Transport in Laminar/Turbulent Flows. MECOM 2012, Salta, Argentina, 2012.

2. Jaworski A.J., Meng G., On-line measurement of separation dynamics in primary gas/oil/water separators: Challenges and technical solutions-A review, Journal of Petroleum Science and Engineering, 68, 47-59, 2005.

3. Jeelani S. A. K. and Hartland S., Effect of Dispersion Properties on the Separation of Batch Liquid-Liquid Dispersions, Ind. Eng. Chem. Res, 37, 547-554, 1998.

4. Kang W, Guo L., Fan H., Meng L., Li Y., 2011, Flocculation, coalescence and migration of dispersed phase droplets and oilwater separation in heavy emulsion, Journal of Petroleum Science and Engineering, 81, 177-181.

5. Lee C., Frankiewicz T., The Design of Large Diameter Skim Tanks Using Computational Fluid Dynamics (CFD) For Maximum Oil Removal, 15th Annual Produced Water Seminar, Houston, USA, 2005

6. Lee D. W., Bateman W.J.D, Owens N., 2007, Efficiency of Oil/Water Separation Controlled by Gas Bubble Size and Fluid Dynamics within the Separation Vessel, GLR Solutions, Calgary, Canada, 2007.

7. Lee D. W., Bateman W.J.D, Owens N., 2007, Efficiency of Oil/Water Separation Controlled by Gas Bubble Size and Fluid Dynamics within the Separation Vessel, GLR Solutions, Calgary, Canada, 2007.

8. ANSYS.ANSYS CFX-Solver Theory Guide, 14th edition, ANSYS Inc., 2018. 